\title{
Robust, Bridge-less Ion-selective Electrodes with Significantly Reduced Need for Pre- and Post-application Handling
}

\author{
Benjamin Schazmann \\ Technological University Dublin, benjamin.schazmann@tudublin.ie \\ S. Demey \\ Technological University Dublin \\ Z. Waqar Ali \\ Technological University Dublin
}

See next page for additional authors

Follow this and additional works at: https://arrow.tudublin.ie/scschcpsart

Part of the Chemistry Commons, and the Physics Commons

\section{Recommended Citation \\ B. Schazmann, S. Demey, Z. W. Ali, M.-S. Plissart, E. Brennan, A. Radu, Electroanalysis 2018, 30, 740. DOI: 10.1002/elan.201700716}

This Article is brought to you for free and open access by the School of Chemical and Pharmaceutical Sciences at ARROW@TU Dublin. It has been accepted for inclusion in Articles by an authorized administrator of ARROW@TU Dublin. For more information, please contact arrow.admin@tudublin.ie, aisling.coyne@tudublin.ie, gerard.connolly@tudublin.ie.

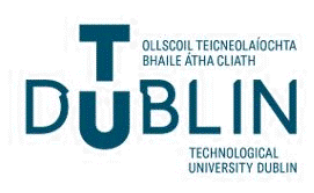


Authors

Benjamin Schazmann, S. Demey, Z. Waqar Ali, M-S Plissart, E. Brennan, and A. Radu

This article is available at ARROW@TU Dublin: https://arrow.tudublin.ie/scschcpsart/123 


\title{
Robust, Bridge-less Ion-selective Electrodes with Significantly Reduced Need for Pre- and Post-application Handling
}

\author{
B. Schazmann, ${ }^{*[a]}$ S. Demey, ${ }^{[a]}$ Z. Waqar Ali, ${ }^{[a]}$ M-S. Plissart,${ }^{[a]}$ E. Brennan, ${ }^{[a]}$ and A. Radu*[b]
}

\begin{abstract}
We are demonstrating robust, single-layer ionselective electrode (ISE) utilizing simple $\mathrm{Ag} / \mathrm{AgCl}$ electrode as solid support without the need for intermediate polymer layer. We have created and chemically linked a family of imidazolium ionic liquids (ILs) with poly (vinyl chloride) (PVC) using click chemistry, resulting in hybrid materials with tunable characteristics. The resultant material inherently contains chloride ion thus offering the ability to stabilize interfacial potential. This allowed us to construct very simple, single-layer membranes with significantly reduced need for conditioning as an added bonus compared to traditional sensors. Chemical immobilization of ISE membrane components also led to extended
\end{abstract}

Keywords: Ion-selective electrode $\cdot$ Sensors $\cdot$ Ionic Liquids lifetime as the potential for material loss is reduced and detection limits are lowered. In our characterization we focused on perchlorate as a model ion. It's levels of around $10^{-7} \mathrm{M}$ could be repeatedly quantified over a 100 day period despite constant exposure of ISEs to aqueous solution over this time. Most importantly, the electrodes exhibited stable and reproducible signal with significantly simplified pre- and post-operation handling protocols. This offers potential for in situ applications as well as to advanced fabrication techniques and miniaturization. Simplicity of construction and operation, and low cost of the solid substrate allows for disposable ISE formats.

\section{Introduction}

The need for developing sensors that can offer measurements much more extensively and frequent than currently possible [1] is placing significantly more importance on solving the issue of simplicity of sensors and sensor handling. This becomes much more important when considering the true cost of the sensor which also includes the time needed for training of technical personnel to handle sensors and sensor-personnel contact time. Complex handling protocols increase the total sensor price and it is therefore critical to develop sensors that require minimal or no pre- and post-operation handling.

Polymer membrane-based ion selective electrodes (ISEs) have many characteristics that make them excellent candidates for routine analysis and early warning systems. They are very simple for operation, have wide dynamic range spanning up to 9 orders of magnitude, do not need energy for operation except for data acquisition circuitry, are not influenced by sample turbidity, and can be miniaturized $[2,3]$. Despite significant advances, problems remained in terms of signal stability, and sensor robustness and handling. Signal stability has indirectly been addressed by the work leading to miniaturization; intermediate liquid layer has been substituted by a variety of materials that stabilized interfacial potential between the membrane and solid electrode. The materials included self-assembled monolayers [4], conductive polymers [2], carbon paste [6], and/or carbon nano-tubes (CNTs) [7].
Leaching of membrane components has been identified as another major source of signal instability [8]. One of the major strategies developed to combat this problem were to covalently attach ionophore or ion exchanger to the polymer matrix [9], and/or develop plasticizer-free membranes $[8,10-12]$. Another approach was to develop carefully designed experimental protocols for handling the sensors including pre- and post-application [13]. Interesting approaches to demonstrate calibration-free and/or condition-free electrodes, hence requiring significantly simplified handling protocols, were described by Bakker [14] and Rich [15] respectively. Mendecki et al have developed an interesting new material based on polymerized ionic liquid that contains iodide ion as the counterion to triazole moiety as the cationic part of the IL [16]. This allowed them to demonstrate single component iodide-selective electrodes that do not require conditioning.

[a] B. Schazmann, S. Demey, Z. W. Ali, M.-S. Plissart, E. Brennan School of Chemical and Pharmaceutical Sciences, Dublin Institute of Technology, Kevin Street, Dublin 8, Ireland E-mail: Benjamin.Schazmann@dit.ie

[b] A. Radu

Lennard-Jones Laboratories, Birchall Centre, Keele University, Keele, Staffordshire ST5 5BG, United Kingdom E-mail: a.radu@keele.ac.uk

Supporting information for this article is available on the WWW under https://doi.org/10.1002/elan.201700716 
Here, we describe a strategy to develop ISEs that require a very simple conditioning protocol and offer excellent signal stability and robustness. We base our work around the development of a family of new imidazolium based Ionic Liquid (IL)-polymer hybrid materials. ILs are chosen due to their versatility and tunable physico-chemical properties [17-19]. In other words, the ability of ILs to undergo almost unlimited structural variations [20], opens up exciting new pathways for their utilization in sensing. For example, modification of ILs can lead to tuning for example of the membrane's polarity, thus dictating it's selectivity [21]. A very interesting concept of development of stable reference electrodes utilizing ILs as salt bridges has been reported in a number of groups. For example, Snook et al demonstrate that dissolution of a low amount of silver trifuoromethanesulfonate (AgTf) in 1-butyl-1-methyl-pyrrolidinium bis(trifuoromethanesulfonyl)imide $\left(\mathrm{P}_{14}\right.$ TFSI) can result in an $\mathrm{Ag} / \mathrm{Ag}^{+}$reference electrode [22], while Kakiuchi et al. create stable $\mathrm{Ag} / \mathrm{AgCl}$ electrode by dissolution of small amount of $\mathrm{AgCl}$ salt in 1-methyl-3-octylimidazolium bis(trifluoromethylsulfonyl)imide $([\mathrm{C}(8) \mathrm{mim}+]$ $[\mathrm{C}(1) \mathrm{C}(1) \mathrm{N}-])$ [23]. We are demonstrating here that due to the presence of $\mathrm{Cl}^{-}$as anionic part our polyimmidazolium-based family of ILs, they behave as salt bridges. This renders the interface potential at the IL $\mid \mathrm{AgCl} / \mathrm{Ag}$ phase boundary stable and therefore enabled us to demonstrate very simple ISEs where the membrane is directly deposited on the $\mathrm{Ag} / \mathrm{AgCl}$ solid support. Consequently, this significantly simplifies preand post-application processing.

\section{Experimental}

\subsection{Reagents, Materials, and Equipment}

1-methyl imidazole, 1-butyl imidazole, propargyl chloride, high molecular weight poly (vinyl chloride) (PVC), sodium azide, ascorbic acid, copper sulphate pentahydrate, 2-nitrophenyl octyl ether (NPOE), sodium hypochlorite, methanol, dimethylformamide (DMF) and anhydrous tetrahydrofuran (THF) were supplied by Sigma Aldrich. Analytical grade sodium or potassium salts of fluoride, chloride, acetate, nitrate, bromide, iodide, perchlorate, thiocyanate and sulphate were supplied by Sigma Aldrich. Milli-Q-purified distilled water was used. All chemicals were used as supplied without further purification.

IR spectra were taken using an FT-IR (ATR module) spectrometer (Perkin Elmer Spectrum 65). Thermogravimetric analysis (TGA) was conducted using a Shimadzu DTG-60 instrument. NMR spectra were obtained using a Bruker $400 \mathrm{MHz}$ (Ultrashield). Elemental analysis was carried out using a Thermo Scientific CHNS/O analyser (Flash 2000). Mass Spectrometry (MS) was performed using $20 \%$ acetonitrile in water (\% v/v) containing $15 \mathrm{mM}$ sodium formate and $5 \mathrm{mM}$ formic acid, as sample solvent. An Agilent 6410 Triple Quad MS instrument was used. ISE measurements were carried out using a doublejunction $\mathrm{Ag} / \mathrm{AgCl} / 3 \mathrm{M} \mathrm{KCl} / 1 \mathrm{M} \mathrm{LiOAc}$ as a reference electrode (Thermo Scientific Orion 900200 Sure-Flow D/ J). The polymer membrane ISEs were fabricated as indicated below. Electrochemical measurements were performed at ambient temperature using a Lawson Labs EMF-16 potentiometer. Voltammetry was performed on a $\mathrm{CH}$ Instruments, Inc. potentiostat model CHI $600 \mathrm{~A}$.

\subsection{Membrane Preparation and Polymer ISE Fabrication}

ISE membrane cocktails were prepared using two types of PVC-IL hybrid material synthesized as described below (PVC-1 and PVC-2 as in Scheme 1). Membranes contained $33 \%$ wt of either of the hybrid material mixed with $66 \%$ wt of NPOE. The mixtures were dissolved in $1 \mathrm{ml}$ of THF. For Coated Wire Electrode (CWE) fabrication, $3 \mathrm{~cm}$ lengths of silver wire $(1 \mathrm{~mm}$ diameter) were used. Nail varnish was used as a dielectric to seal the silver wire leaving $5 \mathrm{~mm}$ of bare silver at the lower and upper ends. The latter was used for connection to the potentiometer wires using crocodile clips. The distal $5 \mathrm{~mm}$ of clean $\mathrm{Ag}$ wire was immersed in $5 \% \mathrm{w} / \mathrm{v}$ sodium hypochlorite for 10 minutes followed by rinsing in de-ionised water. It was then repeatedly dip coated with required membrane cocktail to build up a bead completely covering the $\mathrm{AgCl}$ layer. THF was allowed to evaporate between coats.

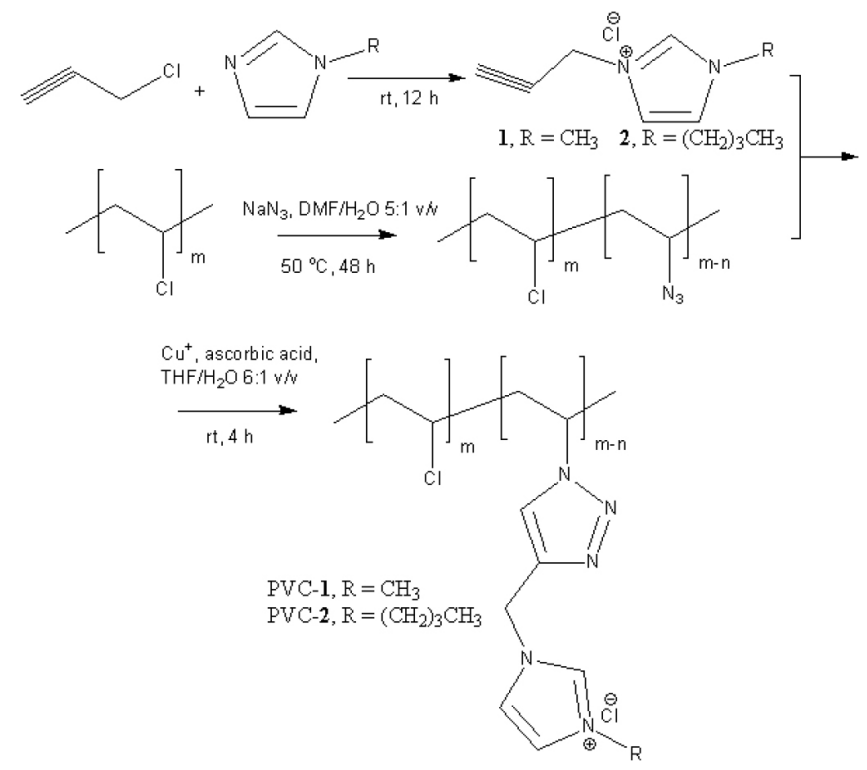

Scheme 1. Reaction of alkylimidazole with propargyl chloride.1, $\mathrm{R}=\mathrm{CH}_{3}$ and $2, \mathrm{R}=\left(\mathrm{CH}_{2}\right)_{3} \mathrm{CH}_{3}$. This was followed by cycloaddition to azidated PVC to form PVC-1, $\mathrm{R}=\mathrm{CH}_{3}$ and PVC-2, $\mathrm{R}=\left(\mathrm{CH}_{2}\right)_{3} \mathrm{CH}_{3}$.

Blank planar SC-ISEs were based on polyethylene terephthalate (PET) screen printed with carbon tracks and a dielectric as described elsewhere [24]. The electrochemical deposition of $\mathrm{Ag}$ and $\mathrm{AgCl}$ layers onto the 
carbon electrode contacts was performed in house (supplemental data). A $300 \mu \mathrm{m}$ thick polypropylene sealing Layer was glued on top of the SC-ISE platforms using epoxy resin, leaving a $3 \mathrm{~mm}$ wide circular well hole above each electrode contact. Sufficient track exposure was allowed at the opposite end of the electrodes, for connection to the potentiometer via crocodile clips. THF based membrane cocktails were now added in $5 \mu \mathrm{l}$ portions, allowing 10 minutes evaporation between additions, until the wells were deemed visually full.

\subsection{Synthetic Procedures}

\subsubsection{1-Propargyl-3-Methylimidazolium Chloride (1)}

A $50 \mathrm{ml}$ round bottomed flask placed in an ice bath was purged with dry nitrogen for 5 minutes and then sealed. 1Methyl imidazole (1.5 g, $0.0182 \mathrm{~mol})$ was added and left to cool for 3 minutes. Propargyl chloride $(1.5 \mathrm{~g}, 0.020 \mathrm{~mol})$ was added slowly using a syringe. The mixture was stirred magnetically for 10 minutes at $0^{\circ} \mathrm{C}$. The mixture is heated to $70^{\circ} \mathrm{C}$ for 10 minutes and then, following removal of the heat source, the mixture is allowed to stir at ambient temperature overnight. The mixture is placed on a rotary evaporator for 20 minutes at $80^{\circ} \mathrm{C}$ to remove unreacted starting material. The product was used with no further purification. $2.7 \mathrm{~g}$ of a dark brown viscous liquid was obtained representing a yield of $94 \% . v_{\max }$ (FT-IR-ATR)/ $\mathrm{cm}-13380,3141,3076,2936,2117,1566,1162,748,621 . \delta_{\mathrm{H}}$ (400 MHz; MeOD; Me4Si) $9.13(1 \mathrm{H}, \mathrm{s}, \mathrm{NCHN}), 7.73(1 \mathrm{H}$, $\mathrm{m}, \mathrm{N}+\mathrm{CHCHN}), 7.66(1 \mathrm{H}, \mathrm{m}, \mathrm{N}+\mathrm{CHCHN}), 5.19(2 \mathrm{H}, \mathrm{s}$, $\mathrm{N}+\mathrm{CH} 2 \mathrm{C}), 3.97(3 \mathrm{H}, \mathrm{s}, \mathrm{NCH} 3), 3.33(1 \mathrm{H}, \mathrm{m}, \mathrm{CH} 2 \mathrm{CCH})$. 13C (100 MHz,MeOD): 138.9, 125.3, 123.4, 78.9, 75.7, 40.0, $36.8 \mathrm{ppm}$. ESI MS $+\mathrm{m} / \mathrm{e} 121.0([\mathrm{M}-\mathrm{Cl}-]$, calcd 121.1).

\subsubsection{1-Propargyl-3-Butylimidazolium Chloride (2)}

An identical procedure as that for the synthesis of 1propargyl-3-methylimidazolium chloride was used with the following proportions of starting materials: 1-butyl imidazole $(2.25 \mathrm{~g}, 0.018 \mathrm{~mol})$ was reacted with propargyl chloride $(1.5 \mathrm{~g}, 0.02 \mathrm{~mol}) .3 .4 \mathrm{~g}$ of a dark brown viscous liquid was obtained representing a yield of $95 \% . v_{\max }$ (FTIR-ATR)/cm-13389, 3079, 2956, 2933, 2870, 2118, 1564, 1454, 1158, 750, 618. $\delta_{\mathrm{H}}(400 \mathrm{MHz}$; CD3CN; Me4Si) 9.89 $(1 \mathrm{H}, \mathrm{s}, \mathrm{NCHN}), 7.71(1 \mathrm{H}, \mathrm{m}, \mathrm{N}+\mathrm{CHCHN}), 7.65(1 \mathrm{H}, \mathrm{m}$, $\mathrm{N}+\mathrm{CHCHN}), 5.33(2 \mathrm{H}, \mathrm{s}, \mathrm{N}+\mathrm{CH} 2 \mathrm{C}), 4.27(2 \mathrm{H}, \mathrm{t}$, $\mathrm{NCH} 2 \mathrm{CH} 2), 3.22(1 \mathrm{H}, \mathrm{m}, \mathrm{CH} 2 \mathrm{CCH}), 1.86(2 \mathrm{H}, \mathrm{m}$, $\mathrm{CH} 2 \mathrm{CH} 2 \mathrm{CH} 2), 1.34$ (2H, m, CH2CH2CH3), 0.94 (3H, s, NCH3). 13C (100 MHz, CD3CN): 136.2, 122.3, 121.7, 76.8, 74.7, 48.9, 38.4, 31.2, 18.6, 12.3 ppm. ESI MS + m/e 163.0 ([M-Cl-], calcd 163.1).

\subsubsection{Azide Functionalised PVC (PVC-azide)}

PVC $(5.0 \mathrm{~g}, 0.08 \mathrm{~mol}$ monomer), sodium azide $(5.2 \mathrm{~g}$, $0.08 \mathrm{~mol})$ and $210 \mathrm{ml}$ of a DMF/water $(5: 1 \mathrm{v} / \mathrm{v})$ mixture were added to a $250 \mathrm{ml}$ round bottomed flask. The flask was slowly purged with dry nitrogen for 5 minutes. The stirring mixture is heated to $50^{\circ} \mathrm{C}$ under nitrogen. After 5, 24, 48, 70 and 117 hours, $30 \mathrm{ml}$ aliquots of reaction mixture are removed from the reaction vessel and allowed to cool to room temperature. The solid is filtered out under vacuum and 3 times alternately washed with $20 \mathrm{ml}$ de-ionised water and $20 \mathrm{ml}$ methanol. The resulting white solid was dried in an oven at $60^{\circ} \mathrm{C}$ for 2 hours resulting in $4.2 \mathrm{~g}$ of product. Subsequent repeat reactions were terminated after 48 hours. $v_{\max }$ (FT-IR-ATR)/cm-12966, 2909, 2108, 1426, 1253, 957, 607.

\subsection{Immobilising Ionic Liquids on PVC (PVC-IL)}

\subsubsection{PVC-1}

Into a $250 \mathrm{ml}$ volumetric flask were added $\mathbf{1}(0.76 \mathrm{~g}, 4.9 \times$ $\left.10^{-3} \mathrm{~mol}\right)$, PVC-azide $(0.97 \mathrm{~g})$, copper sulphate pentahydrate $\left(0.44 \mathrm{~g}, 1.76 \times 10^{-3} \mathrm{~mol}\right)$ and ascorbic acid $(1.5 \mathrm{~g}$, $\left.8.5 \times 10^{-3} \mathrm{~mol}\right)$ in $83 \mathrm{ml}$ of a THF/water mixture $(6: 1 \mathrm{v} / \mathrm{v})$. The solution is stirred at room temperature for 4 hours. De-ionised water was added to precipitate out a solid. The solid is filtered out under vacuum and washed 5 times with $10 \mathrm{ml}$ de-ionised water. The resulting solid was dried in an oven at $60^{\circ} \mathrm{C}$ for 3 hours. The solid was then dissolved in $30 \mathrm{ml}$ THF and any insoluble solids removed by vacuum filtration. The filtrate was treated with deionised water to precipitate out the solid product. The solid was recovered by vacuum filtration and washed 3 times with $10 \mathrm{ml}$ de-ionised water. The resulting solid was dried in an oven at $60^{\circ} \mathrm{C}$ for 3 hours. $0.65 \mathrm{~g}$ of a fibrous white solid was recovered. $v_{\max }$ (FT-IR-ATR)/cm-12971, 2909, 2110, 1426, 1252, 964, 612. Anal. found: C, 37.88; N, 0.67 .

\subsubsection{PVC-2}

An otherwise identical procedure as that for the synthesis of PVC-1 was used with the following starting materials: 2 $\left(1.12 \mathrm{~g}, \quad 5.6 \times 10^{-3} \mathrm{~mol}\right)$ was reacted with $\mathrm{PVC}$-azide $(1.30 \mathrm{~g}) .0 .99 \mathrm{~g}$ of a fibrous white solid was recovered. $v_{\max }$ (FT-IR-ATR)/cm-12969, 2917, 2108, 1424, 1249, 969, 689. Anal. found: C, 38.27; N, 0.61.

\subsection{Electrochemical Measurements}

ISEs were conditioned in $0.01 \mathrm{M} \mathrm{NaCl}$ overnight (unless stated otherwise) and in de-ionised water for 30 minutes prior to first use. A titrations sequence following the Hofmeister series was followed with the least lipophilic anions tested first. ISE titrations were carried out in the range $\log \mathrm{a}=-9$ to -1 for each anion tested. Observed potentials were recorded once stabilised and the time noted. Electrodes were stored in $0.01 \mathrm{M} \mathrm{NaCl}$ following first use. Selectivity coefficients were calculated using the Separate Solutions Method (SSM) [25]. Activity coefficients $(\log$ a) were calculated according to the Debye- 
Hückel approach and voltages were corrected for liquidjunction potentials with the Henderson equation.

\section{Results and Discussion}

Our synthesis started with the combination of methyl- or butyl imidazole with alkylating agent propargyl chloride to yield room temperature ILs 1 and 2. The choice of an exchangeable chloride as counteranion was to fulfil the role of messenger to an electrode's underlying silver-silver chloride $(\mathrm{Ag} / \mathrm{AgCl})$ electronic conductor, a role traditionally facilitated by chloride based filling solutions [26]. Scheme 1 shows the reaction scheme.

The purity of $>95 \%$ was verified in all cases by $1 \mathrm{H}$ NMR spectrum (Supplemental data Figure S-S4). Although alkyne bearing imidazolium ionic liquids have been prepared before including PVC-1 [27] we believe we are the first to synthesise PVC-2. Furthermore, we are the first to graft such ILs onto a polymer backbone for the purpose of incorporation into an electrode. With alkyne containing PVC-1 and PVC-2 in place, we focussed on preparing the PVC-azide precursor material (Scheme 1) based on an existing method [28] The strategy was to substitute chlorine atoms along the PVC backbone with azide functionality. Figure 1 below shows the FT-IR spectra of the product at the indicated time points focussing on the region containing the characteristic strong azide stretch signal at around $2100 \mathrm{~cm}^{-1}$ and a strong $\mathrm{C}-\mathrm{H}$ stretch between $2900-3000 \mathrm{~cm}^{-1}$, the latter attributable to the $\mathrm{C}-\mathrm{H}$ bonds in the PVC backbone.

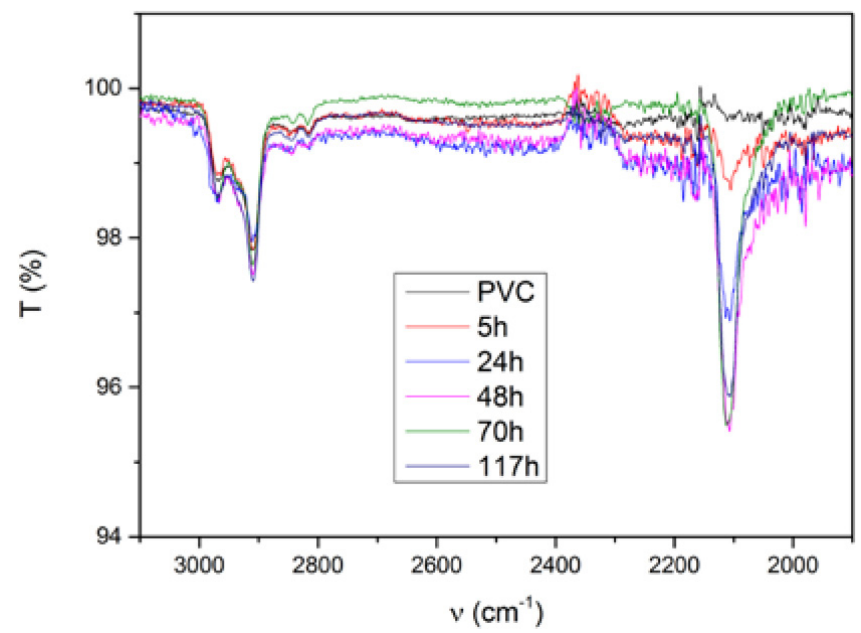

Fig. 1. FT-IR spectra of pure PVC and PVC-azide at the indicated reaction time points. The signal at $2100 \mathrm{~cm}^{-1}$ corresponds to the azide functional group.

The $\mathrm{C}-\mathrm{H}$ stretch band remains quite constant for pure PVC and all reaction product time intervals as expected. Conversely, the azide signal at $2100 \mathrm{~cm}^{-1}$ increases up to 48 hours reaction time, suggesting that no more azide functionality is being added to the PVC backbone after this point.

Thermogravimetric analysis (TGA) of the PVC-azide reaction products supported the above observation of reaction progress (Supplemental data Figure S5). The TGA trace of PVC starting material shows the familiar loss of chlorine at about $310^{\circ} \mathrm{C}$ [29]. The TGA trace profile does not change further after 48 hours suggesting a reaction end, in agreement with the IR data.

Following reaction of PVC with sodium azide for at least 48 hours, 1 or 2 were separately reacted with PVCazide to produce hybrid materials PVC-1 and PVC-2 (Scheme 1). The reaction proceeded via copper(I) catalysed Huisgen 1,3-dipolar cycloaddition reaction $(\mathrm{Cu}-$ CAAC), a prime reaction in the click chemistry arsenal [30-32]. Here a terminal alkyne reacts with an azide to form a regioselective triazole linker between the two. Yields are often greater than $95 \%$, minimal purification steps are required and the reaction can be conducted in many solvents including water.

A general solubility of no less than $50 \mathrm{mg} / \mathrm{ml} \mathrm{THF}$ at room temperature was deemed acceptable for polymeric materials used in electrodes [33]. PVC-2 surpasses this level of solubility, with a solubility of about $80 \mathrm{mg} / \mathrm{ml}$, whereas PVC-1 had an estimated solubility of only around $30 \mathrm{mg} / \mathrm{ml}$ THF. It is assumed that the azide-alkyne click reaction of the final stage proceeds quantitatively, with the initial degree of substitution of PVC chlorines being the limiting step [33]. This was confirmed by FT-IR after 4 hours of reaction. For both PVC-1 and PVC- 2 we see the virtual disappearance of the azide peak at $2100 \mathrm{~cm}^{-1}$ with a concurrent appearance of a $\mathrm{C}=\mathrm{N}$ bond stretch at $1640 \mathrm{~cm}^{-1}$ from the expected triazole formation, when compared to the PVC azide start material (Supplemental data Figure S6).

We performed a CHN analysis on PVC-1 and PVC-2 to estimate the degree of substitution onto PVC. The content of triazole-imidazolium fragments was estimated to be $1.9 \mathrm{~mol} \%$ and $2.1 \mathrm{~mol} \%$ respectively (calculation revolves around $\mathrm{N}$ content). In other words, about 1 in every 170 vinyl chloride units becomes substituted with triazole-imidazolium. A similar maximum order of magnitude substitution $(6.1 \%)$ was observed by other investigators performing azidation of PVC [33]. These figures may appear subtle but dramatic changes in physical and chemical properties compared to relatively inert PVC were observed.

\subsection{Sensing Characteristics of ISEs Based on PVC-IL Hybrid Material}

\subsubsection{Selectivity}

In order to determine selectivity coefficients of our hybrid-based electrodes, they were conditioned overnight in $0.01 \mathrm{M}$ of $\mathrm{NaCl}$. Note that our membranes are ionophore-free and therefore it is expected that they behave as pure ion-exchange membrane. In other words, 
responses according to Hofmeister series $\left(\mathrm{SCN}^{-}>\right.$ $\mathrm{ClO}_{4}{ }^{-}>\mathrm{I}^{-}>\mathrm{Br}^{-}>\mathrm{NO}_{3}{ }^{-}>\mathrm{Cl}^{-}>\mathrm{AcO}^{-}>\mathrm{SO}_{4}{ }^{2-}$ ) [34] were expected. Observation of Nernstian response slopes for all ions is critical for obtaining unbiased selectivity coefficients [25]. Figure 2 shows the response of PVC-1 and PVC-2 to a series of anions in water. Both electrodes exhibited minimal $\mathrm{pH}$ sensitivity (as per Figure S7 in Supplemental Information, observed slopes are -7.5 and $-3.8 \mathrm{mV} /$ decade for PVC-2 and PVC-1 respectively).
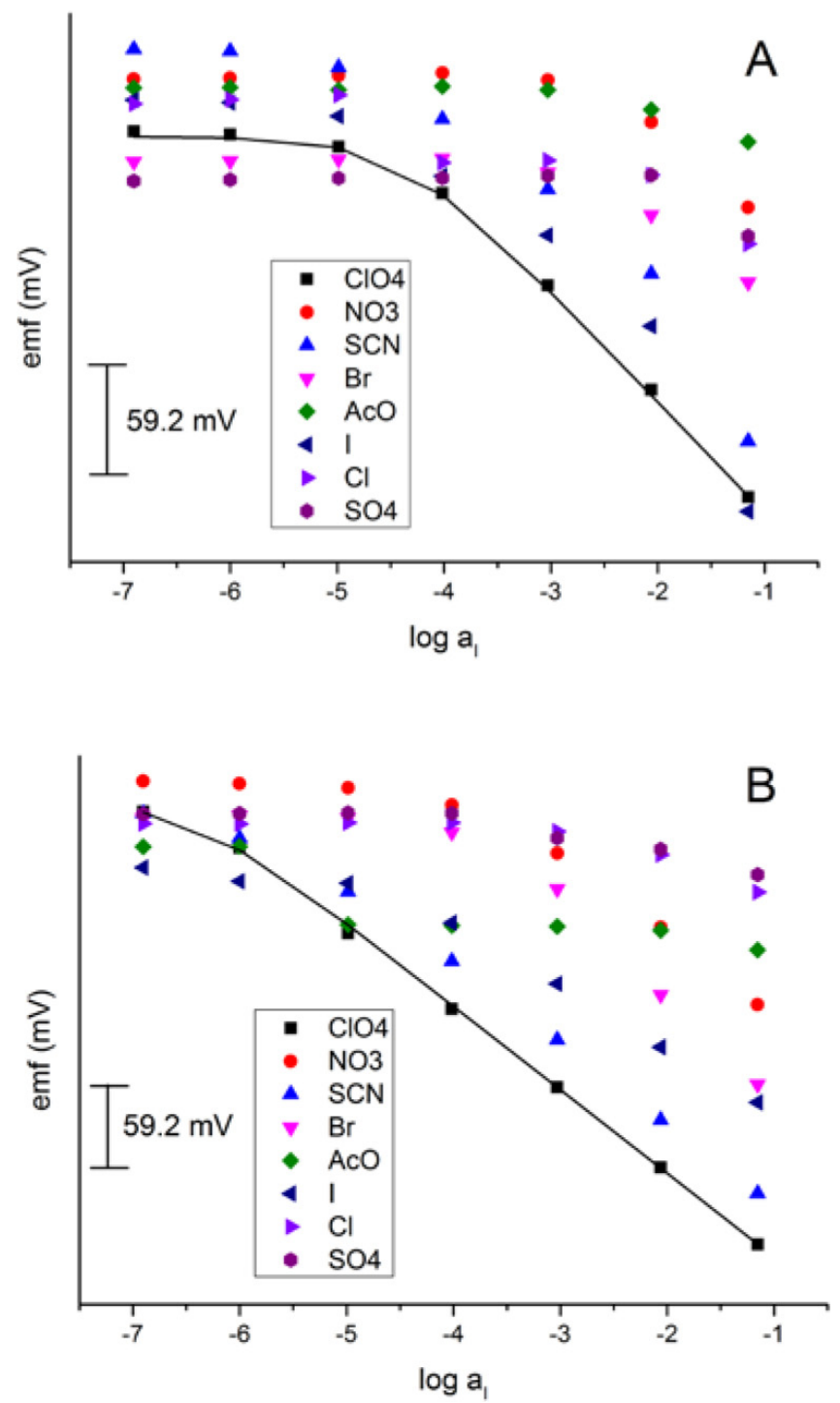

Fig. 2. The response of ISEs based on a) PVC-1 and b) PVC-2 to a series of anions in the background of deionized water. Only response to $\mathrm{ClO}_{4}^{-}$is outlined as electrodes were characterized as $\mathrm{ClO}_{4}^{-}$-selective (see text).

Detailed information on response slopes and linearity range is provided in Supplemental Information (Table S1). In general, close-to-Nernstian slopes were observed in almost all cases except for $\mathrm{AcO}^{-}$which allowed us to calculate unbiased selectivity coefficient as discussed by
Bakker [25]. Observation of non-Nernstian response is not surprising considering ease of its transport through PVC-based membranes and induced drift [35]. It is interesting that response to perchlorate appears enhanced thus making electrodes slightly perchlorate-selective. Interestingly, PVC-2 exhibits larger response ranges of all ions. For example, limit of detection (LOD) to $\mathrm{ClO}_{4}{ }^{-}$is $\sim 10^{-7} \mathrm{M}(\sim 10 \mathrm{ppb})$ which is almost 3 orders of magnitude lower that for electrodes based on PVC-1. This is most likely because the polymer in PVC-2 is functionalized by more lipophilic butyl as opposed to less lipophilic methyl group as in PVC-1. The increased lipophilicity of the polymer enhances response range [36,37]. Selectivity to $\mathrm{ClO}_{4}^{-}$is an important observation considering the importance of perchlorate in safety and security, and environment $[38,39]$ and even in extra-terrestrial research $[40,41]$. Therefore, having robust electrodes with LOD of $\sim 10 \mathrm{ppb}$ that do not require any pre- or post-operational handling would be highly beneficial.

\subsubsection{Signal Robustness}

Classical ISEs based on traditional metal chloride (e.g. $\mathrm{Ag} / \mathrm{AgCl}$ or calomel $\mathrm{Hg}_{2} \mathrm{Cl}_{2}$ ) exhibit necessity to have chloride (or halogen) present in inner filling solutions in order for the underlying metallic electrode and electron conductor to communicate with ion based filling solution and the membrane. We anticipated that the mobile/ exchangeable chloride counteranion in PVC-1 and PVC-2 would serve as appropriate messengers between the solid contact $\mathrm{Ag} / \mathrm{AgCl}$ electrode surface and the inner face of the polymer membrane. We therefore proceed on this basis, entirely leaving out a separate intermediate layer.

In early work with the so called coated wire electrodes ( $\mathrm{Ag} / \mathrm{AgCl}$ electrode simply coated with selective membrane) potential instabilities were observed. They were attributed to the formation of oxygen half-cell at the inner electrode [42,43], lack of well-defined redox couple [42], and formation of a thin water layer at the membrane/ electrode interface [5]. Fibbioli et al demonstrated that alternating exposure to primary and interfering ions results in observation of strong drifts in response of ISEs as a result of formation of the water layer [5]. We have designed a slightly modified experimental protocol in order to address factors that are out of experimental control (e.g. thickness, homogeneity, and composition of aqueous water layer as well as membrane thickness and diffusion coefficient). Figure 3 shows responses of PVC-1 and PVC-2 exposed to solutions containing $\mathrm{Cl}^{-}$and $\mathrm{ClO}_{4}^{-}$ as interfering and primary ions respectively. Stable responses confirmed our expectations for well-defined redox couple at the $[\operatorname{Imim}][\mathrm{Cl}] \mid \mathrm{AgCl} / \mathrm{Ag}$ phase boundary. Our hybrid material thus acts as salt bridge due to the inherent presence of $\mathrm{Cl}^{-}$in the membrane. An interesting and welcome consequence is the absence of water layer.

This is most likely due to increased hydrophobicity of immobilized PVC-IL hybrid which reduces the transfer of water through the membrane. The absence of oxygen half- 


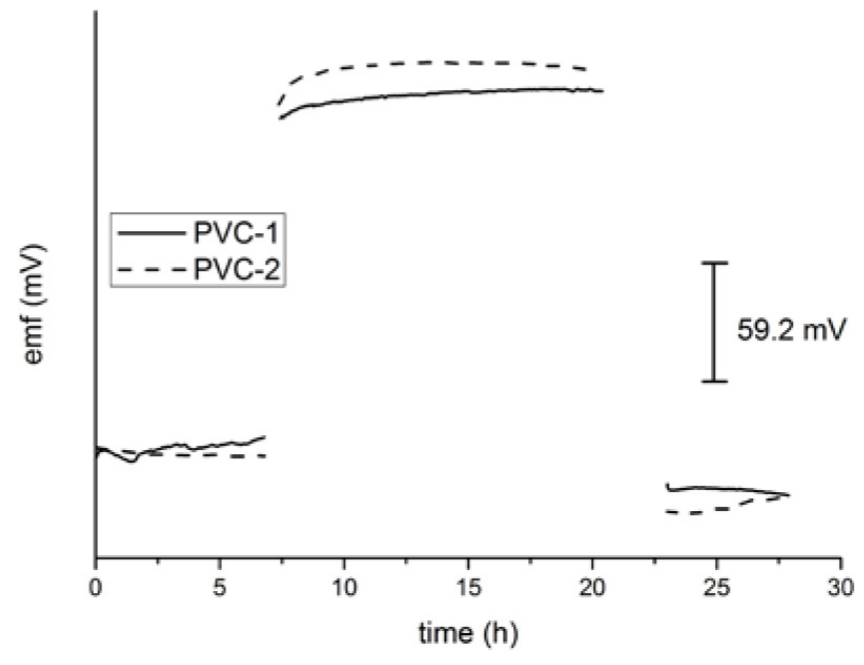

Fig. 3. The water layer test was performed by exposing unused electrodes PVC-1 and PVC-2 first to $1 \times 10^{-3} \mathrm{M}$ potassium salt of primary ion such as $\mathrm{ClO}_{4}^{-}$up to 6 hours and then to $\mathrm{Cl}^{-}$for about 20 hours. The step-wise potential response pattern indicates an absence of zero current ion fluxes.

cell is also confirmed (see Figure S8 in SI) thus demonstrating that ISEs based on our hybrid material exhibit excellent signal stability.

Encouraged by these results, we have decided to further test signal reproducibility. This was done by cycling between solutions of low and high $\mathrm{ClO}_{4}{ }^{-}$concentration, namely between $\operatorname{Lod} g=-6.5$ and $\log \mathrm{a}=-4$. This was done on both conditioned and non-conditioned electrodes. Figure 4 compares responses of conditioned and non-conditioned (used dry 'out of the box') PVC-2. It

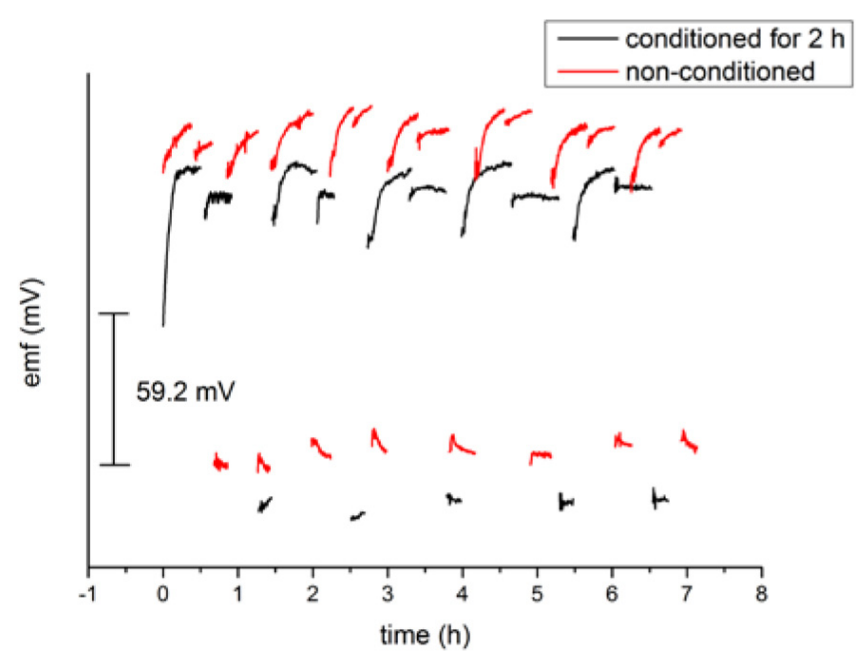

Fig. 4. Reproducibility of PVC-2 for conditioned and non-conditioned ISEs. Where applicable, PVC-2-based electrodes were conditioned in $1 \times 10^{-5} \mathrm{M}$ perchlorate overnight. All electrodes were first exposed to deionized water, followed by the exposure to the solution at near the LOD $10^{-6.5} \mathrm{M}$, followed by the exposure to the solution of $10^{-4} \mathrm{M}$. The cycle is repeated for at least 5 times. Numerical values are provided in Table S2. is noteworthy that there was no significant difference between responses of conditioned and non-conditioned PVC-1 at appropriately chosen response range (results not shown).

It is very exciting that conditioned electrodes show very reproducible responses, thus exhibiting excellent signal robustness. It was also very exciting to observe excellent robustness even with non-conditioned electrodes. Initial drifts most likely originate from the hydration of polymer but the signal stabilizes after conditioning for as little as one hour (data not shown). This indicates that no complex protocols are necessary for handling electrodes post-application as it is commonly required [13]. After calibrating our electrodes in the solution of $\mathrm{ClO}_{4}^{-}$we have simply dried them and kept them in a dry and dark drawer. Prior to next use, electrodes were conditioned for an hour in the solution of $10^{-4} \mathrm{M}$ of $\mathrm{ClO}_{4}^{-}$and the next calibration was performed.

It is known that changing chemical composition within the ISE membrane is a major factor contributing to signal drift of ISEs. Therefore covalent attachment of the main membrane components is expected to reduce their leaching and the ensuing chemical changes in the membrane. A set of calibrated electrodes have been kept in their conditioning solutions and calibration versus a number of ions was then repeated after 100 days. Figure 5 compares these two responses for $\mathrm{ClO}_{4}{ }^{-}$only, while the average response slopes, LODs and selectivity coefficients for all other ions are provided in Table S1. Results are obtained for at least 3 used electrodes. Figure 5 provides response of only one electrode for clarity purpose. No significant deviation of LOD, only minor deviations of slope and selectivity coefficients, and maximal $\mathrm{E}^{0}$ deviation of $5 \mathrm{mV}$ were observed. Note that responses in Figure 5 were artificially shifted in order to provide better illustration of responses. This is a very important observa-

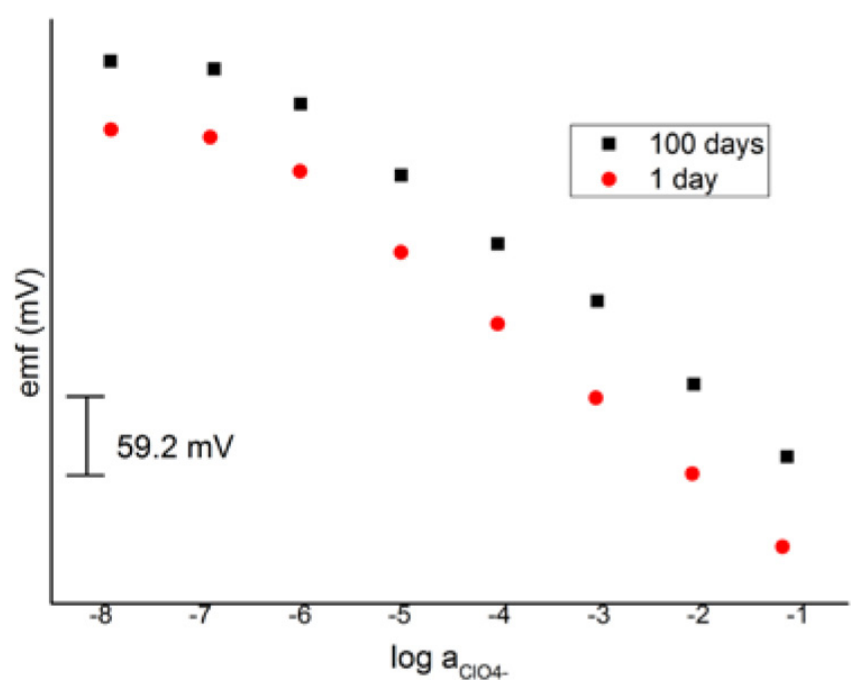

Fig. 5. Responses to $\mathrm{ClO}_{4}^{-}$of PVC-2 based electrodes freshly prepared (red circles; 1 day) and after storage in their conditioning solution for 100 days (black squares). 
tion as it indicates that no observable leaching of components takes places. This would allow development of electrodes with long-term signal stability which is important in for example studying global effects of natural and anthropogenic sources of perchlorate [38,39] or in the search for water on planetary bodies [40].

\section{Conclusions}

This work describes a new simple sensor layer that shows excellent signal robustness. Chloride as the anion part of a polymerized Immidazolium moiety serves as a salt bridge to establish a stable redox couple at the polymer membrane solid $\mathrm{Ag} / \mathrm{AgCl}$ electrode interface. The membrane is not doped with ionophore or ion exchanger and thus exhibited Hofmeister selectivity pattern albeit with slightly increased selectivity for $\mathrm{ClO}_{4}^{-}$. The electrodes demonstrate very good signal robustness and were used over 100 days with minimal handling prior to application and no handling post application.

Excellent reproducibility and the need for only short pre-application handling time (approximately one hour) and completely absent need for post-application handling is highly encouraging for in situ real-life applications. This indicates that once the electrodes based on our hybrid material are prepared the electrode-technician contact time is greatly reduced in comparison to traditional ISEs. This is important when considering total price of analysis. The time required for training of technicians and time needed for handling of electrodes greatly features in cost analysis. In order to offer increased frequency of measurement while reducing per-sample and per-measurement cost, robust sensors that require no pre- and/or postapplication handling can be very advantageous.

\section{Acknowledgements}

We wish to thank the European Erasmus + funding mechanism for enabling students to work in our laboratories at the School of Chemical and Pharmaceutical Sciences in DIT, Dublin, Ireland and at Keele University in the UK. AR gratefully acknowledge support by Royal Society (RG120118).

\section{References}

[1] R. Murray, Anal. Chem. 2010, 82, 1569-1569.

[2] J. Bobacka, A. Ivaska, A. Lewenstam, Chem. Rev. 2008, 108, 329-351.

[3] A. Radu, T. Radu, C. Mcgraw, P. Dillingham, S. AnastasovaIvanova, D. Diamond, J. Serb. Chem. Soc. 2013, 78, 17291761.

[4] M. Fibbioli, K. Bandyopadhyay, S.-G. Liu, L. Echegoyen, O. Enger, F. Diederich, P. Bühlmann, E. Pretsch, Chem. Commun. 2000, 0, 339-340.

[5] M. Fibbioli, W. E. Morf, M. Badertscher, N. F. de Rooij, E. Pretsch, Electroanalysis 2000, 12, 1286-1292.

[6] H. Xu, Y. Pan, Y. Wang, G. Li, Y. Chen, Y. Ye, Meas. Sci. Technol. 2012, 23, 125101.
[7] G. A. Crespo, S. Macho, F. X. Rius, Anal. Chem. 2008, 80, 1316-1322.

[8] Y. Qin, S. Peper, A. Radu, A. Ceresa, E. Bakker, Anal. Chem. 2003, 75, 3038-3045.

[9] M. Püntener, M. Fibbioli, E. Bakker, E. Pretsch, Electroanalysis 2002, 14, 1329-1338.

[10] L. Y. Heng, K. Toth, E. A. H. Hall, Talanta 2004, 63, 73-87.

[11] Y. Qin, S. Peper, E. Bakker, Electroanalysis 2002, 14, 13751381.

[12] L. Y. Heng, E. A. H. Hall, Anal. Chem. 2000, 72, 42-51.

[13] E. Lindner, Y. Umezawa, Pure Appl. Chem. 2008, 80, 85104.

[14] E. Bakker, V. Bhakthavatsalam, K. L. Gemene, Talanta 2008, 75, 629-635.

[15] M. Rich, L. Mendecki, S. T. Mensah, E. Blanco-Martinez, S. Armas, P. Calvo-Marzal, A. Radu, K. Y. ChumbimuniTorres, Anal. Chem. 2016, 88, 8404-8408.

[16] L. Mendecki, X. Chen, N. Callan, D. F. Thompson, B. Schazmann, S. Granados-Focil, A. Radu, Anal. Chem. 2016, $88,4311-4317$.

[17] D. Wei, A. Ivaska, Anal. Chim. Acta 2008, 607, 126-135.

[18] D. R. MacFarlane, J. M. Pringle, K. M. Johansson, S. A. Forsyth, M. Forsyth, Chem. Commun. 2006, 1905-1917.

[19] D. S. Silvester, Analyst 2011, 136, 4871-4882.

[20] S. Ahrens, A. Peritz, T. Strassner, Angew. Chem. Int. Ed. Engl. 2009, 48, 7908-7910.

[21] L. Mendecki, N. Callan, M. Ahern, B. Schazmann, A. Radu, Sensors 2016, 16, 1106.

[22] G. A. Snook, A. S. Best, A. G. Pandolfo, A. F. Hollenkamp, Electrochem. Commun. 2006, 8, 1405-1411.

[23] T. Kakiuchi, T. Yoshimatsu, N. Nishi, Anal. Chem. 2007, 79, 7187-7191.

[24] J. Bobacka, Electroanalysis 2006, 18, 7-18.

[25] E. Bakker, Anal. Chem. 1997, 69, 1061-1069.

[26] E. Bakker, P. Bühlmann, E. Pretsch, Chem. Rev. 1997, 97, 3083-3132.

[27] M. Šorm, M. Procházka, J. Kálal, Collect. Czech. Chem. Commun. 1985, 50, 845-853.

[28] M. Pawlak, E. Grygolowicz-Pawlak, E. Bakker, Anal. Chem. 2010, 82, 6887-6894.

[29] M. N. R. Nair, M. R. G. Nair, J. Therm. Anal. Calorim. 2011, 103, 863-872.

[30] J.-F. Lutz, Angew. Chem. Int. Ed. 2007, 46, 1018-1025.

[31] V. V. Rostovtsev, L. G. Green, V. V. Fokin, K. B. Sharpless, Angew. Chem. Int. Ed. 2002, 41, 2596-2599.

[32] M. A. Gauthier, M. I. Gibson, H.-A. Klok, Angew. Chem. Int. Ed. 2009, 48, 48-58.

[33] E. Grygolowicz-Pawlak, K. Plachecka, Z. Brzozka, E. Malinowska, Sens. Actuators B 2007, 123, 480-487.

[34] F. Hofmeister, Arch. Für Exp. Pathol. Pharmakol. 1888, 24, 247-260.

[35] S. Jadhav, Electrochem. Solid-State Lett. 1999, 1, 194.

[36] C.-Z. Lai, S. S. Koseoglu, E. C. Lugert, P. G. Boswell, J. Rábai, T. P. Lodge, P. Bühlmann, J. Am. Chem. Soc. 2009, 131, 1598-1606.

[37] E. Bakker, M. Lerchi, T. Rosatzin, B. Rusterholz, W. Simon, Anal. Chim. Acta 1993, 278, 211-225.

[38] S. P. Kounaves, S. T. Stroble, R. M. Anderson, Q. Moore, D. C. Catling, S. Douglas, C. P. McKay, D. W. Ming, P. H. Smith, L. K. Tamppari, A. P. Zent, Environ. Sci. Technol. 2010, 44, 2360-2364.

[39] E. T. Urbansky, M. R. Schock, J. Environ. Manage. 1999, 56, 79-95.

[40] M. H. Hecht, S. P. Kounaves, R. C. Quinn, S. J. West, S. M. M. Young, D. W. Ming, D. C. Catling, B. C. Clark, 
W. V. Boynton, J. Hoffman, L. P. De Flores, K. Gospodinova, J. Kapit, P. H. Smith, Science 2009, 325, 64-67.

[41] S. P. Kounaves, M. H. Hecht, S. J. West, J.-M. Morookian, S. M. M. Young, R. Quinn, P. Grunthaner, X. Wen, M. Weilert, C. A. Cable, A. Fisher, K. Gospodinova, J. Kapit, S. Stroble, P.-C. Hsu, B. C. Clark, D. W. Ming, P. H. Smith, J. Geophys. Res. [Planets] 2009, 114, E00A19.

[42] R. W. Cattrall, P. Chin-Poh, Anal. Chem. 1975, 47, 93-95.

[43] A. Hulanicki, M. Trojanowicz, Anal. Chim. Acta 1976, 87, 411-417.
[44] A. Michalska, M. Wojciechowski, E. Bulska, K. Maksymiuk, Talanta 2010, 82, 151-157.

[45] U. Vanamo, J. Bobacka, Anal. Chem. 2014, 86, 10540-10545.

Received: November 6, 2017 Accepted: December 30, 2017 Published online on February 2, 2018 